\title{
INFLUÊNCIA DE LÂMINAS DE IRRIGAÇÃO E FONTES DE NITROGÊNIO NO CRESCIMENTO VEGETATIVO DO TOMATE CEREJA CULTIVADO EM AMBIENTE PROTEGIDO
}

Antonio de Paula dos Santos ${ }^{1}$, Adriana Rodolfo da Costa ${ }^{2}$, Patrícia Costa Silva ${ }^{3}$, Mariana Cristina Rosa de Melo ${ }^{4}$, Hélio Lopes Araújo ${ }^{5}$

${ }^{1}$ Engenheiro Agrícola, pela Universidade Estadual de Goiás - Câmpus Santa Helena de Goiás.

${ }^{2}$ Engenheira Agrônoma, Doutora em Agronomia pela Universidade de Brasília, docente do ensino superior da Universidade Estadual de Goiás - Câmpus Santa

Helena de Goiás. e-mail: adriana_rodolfo@yahoo.com.br

${ }^{3}$ Engenheira Agrônoma, Doutoranda em Agronomia pela Universidade Estadual de São Paulo, docente do ensino superior da Universidade Estadual de Goiás Câmpus Santa Helena de Goiás

${ }^{4}$ Acadêmica do curso de Engenharia Agrícola da Universidade Estadual de Goiás Câmpus Santa Helena de Goiás.

${ }^{5}$ Mestrando em Engenharia Agrícola pela Universidade Federal Rural do Rio de Janeiro.

Recebido em: 08/04/2017 - Aprovado em: 10/06/2017 - Publicado em: 20/06/2017

DOI: 10.18677/EnciBio_2017A65

\section{RESUMO}

O objetivo deste estudo foi avaliar o crescimento vegetativo do tomateiro cereja sob fontes de nitrogênio e lâminas de irrigação em função da evapotranspiração da cultura. O experimento foi conduzido em ambiente protegido da Universidade Estadual de Goiás, Câmpus Santa Helena de Goiás. O delineamento experimental adotado neste ensaio foi o de blocos casualizados em esquema de parcelar subdivididas, com cinco lâminas de irrigação, as quais correspondiam a 50,75, 100, 125 e 150\% da evapotranspiração da cultura (ETc), duas fontes de nitrogênio (1- ureia comum - UC; 2- ureia com inibidor de urease UI) mais uma testemunha nula, ou seja, em nitrogênio (SN), em que aos 21, 34, 42, 53 e 74 dias após o transplantio (DAT) foram mensurados: diâmetro do caule (DC) e altura de plantas (AP). Os dados obtidos foram submetidos à análise de variância e nos casos de significância, realizou-se análise de regressão para o fator lâmina e teste de Tukey para avaliar o efeito de fontes de nitrogênio e DAT. A altura máxima de plantas $(43,54 \mathrm{~cm})$ de tomate cereja cultivado em vasos em ambiente protegido foi atingida com uma lâmina de $111,32 \%$ da ETc. O diâmetro de caule do tomateiro é uma variável pouco sensível ao estresse hídrico. $O$ efeito da adubação nitrogenada em plantas de tomate só foi perceptível aos 42 dias após o transplantio.

PALAVRAS-CHAVE: evapotranspiração; Licopersicum esculentum Mill; ureia com inibidor de uréase 


\title{
INFLUENCE OF IRRIGATION BLADES AND NITROGEN SOURCES IN THE VEGETABLE GROWTH OF CHERRY TOMATO CULTIVATED IN PROTECTED ENVIRONMENT
}

\begin{abstract}
The objective of this study was to evaluate the vegetative growth of the cherry tomato under nitrogen sources and irrigation slides as a function of crop evapotranspiration. The experiment was conducted in a protected environment of the State University of Goiás, Campus Santa Helena de Goiás. The experimental design adopted in this experiment was a randomized complete block design in subdivided, composed of five irrigation slides, which corresponded to 50,75, 100, 125 and $150 \%$ of crop evapotranspiration (ETc), two nitrogen sources (1 common urea - CU, 2- urea with urease inhibitor UI), and one more witness, without nitrogen (WN). In which at 21, 34, 42,53 and 74 days after transplanting (DAT) the diameter of the stem (DC) and plant height (PA) was measured. The data were submitted to analysis of variance and in the cases of significance, regression analysis was performed for the blade factor and Tukey test to evaluate the effect of nitrogen and DAT sources. The maximum height of plants $(43.54 \mathrm{~cm})$ of cherry tomato cultivated in pots of protected environment was reached with a blade of $111.32 \%$ of ETc. The diameter of the tomato is a variable that is not sensitive to water stress. The source of nitrogen, common urea, was more efficient in the use of water in relation to plant height and diameter, as it provided better growth of tomato plants with less water use. The effect of nitrogen fertilization on tomato plants was only perceptible at 42 days after transplanting.
\end{abstract}

KEYWORDS: evapotranspiration; Licopersicum esculentum Mill; Urea with urease inhibitor

\section{INTRODUÇÃO}

O tomateiro pode ser produzido durante todo o ano, é extremamente importante na economia nacional e mundial, tendo em vista seu elevado consumo. Isso se deve ao fato de seus frutos serem ricos em nutrientes, o que ajuda na dieta saudável dos consumidores (GUILHERME et al., 2014). Não só a economia nacional, como também todo o planeta, está passando por mudanças econômicas e adaptações sociais e climáticas, que exigem aumento na produtividade e qualidade dos produtos agrícolas, em especial as hortaliças, e isso pode ser afetado pela adubação e irrigação, fatores, estes que influenciam também o desenvolvimento vegetativo das plantas.

Como é notável a escassez hídrica no país, o uso da irrigação por gotejo na produção agrícola é essencial, pois, pode reduzir perdas de água tanto por percolação quanto por evaporação, o que possibilita uso mais eficiente desse recurso natural. O manejo da irrigação deve ser realizado de modo a respeitar a demanda hídrica da cultura no decorrer de seu ciclo, e uma das formas é estimando a evapotranspiração da cultura (ETc) pelo tanque Classe $A$, porém, devido ao espaço limitado no interior de estufas frequentemente tem-se utilizado minitanques evaporímetros (CAMPAGNOL et al., 2014). De acordo com SOARES et al. (2011) a irrigação controlada é importante para o aumento no rendimento do tomateiro, já que a cultura é sensível tanto à irrigação excessiva quanto insuficiente, tendo em vista 
que ocasionam problemas de ordem fisiológica e de crescimento. Sendo assim, é necessário identificar o nível satisfatório de irrigação para o bom desenvolvimento do tomateiro.

O nitrogênio é um dos nutrientes requeridos em maior quantidade pelas plantas, e sua aplicação pode ser afetada pela perda no solo, segundo CAETANO et al. (2015) estudos com utilização de ureia de liberação lenta ou revestidas com polímeros são incipientes e, por isso, precisam ser mais investigados, especialmente no cultivo de hortaliças de importância econômica como o tomate.

Sendo assim, o objetivo deste estudo foi avaliar o crescimento vegetativo do tomateiro cereja (Lycopersicon esculentum Mill) sob fontes de nitrogênio e lâminas de irrigação em função da evapotranspiração da cultura determinadas por minitanque evaporímetro.

\section{MATERIAL DE MÉTODOS}

O experimento foi conduzido em ambiente protegido (estufa) na área experimental da Universidade Estadual de Goiás, Câmpus Santa Helena de Goiás GO, no Sudoeste Goiano. As coordenadas locais para referências são latitude $17^{\circ}$ 48' 49" S e longitude $50^{\circ} 35^{\prime}$ ' 49" W, com 595 metros de altitude. Nesta região de Cerrado, a precipitação anual tem distribuição bimodal, com duas estações bem definidas: estação seca (maio - outubro) e chuvosa (novembro - abril), sendo, por isso importante proceder a irrigação durante o período de menor disponibilidade hídrica para a realização de cultivos de diferentes culturas.

$O$ delineamento experimental adotado neste ensaio foi 0 de blocos casualizados (DBC) em esquema de parcelas subdivididas com cinco lâminas de irrigação, as quais corresponderam a 50, 75, 100, 125 e 150\% da evapotranspiração da cultura (ETc); duas fontes de nitrogênio (1- ureia comum - UC; 2- ureia com inibidor de urease - UI) mais uma testemunha nula, ou seja, em nitrogênio (SN); repetidas no tempo, com amostragens aos 21, 34, 42, 53 e 74 dias após o transplantio (DAT). Cada parcela era constituída por um vaso de 8 litros, preenchidos com solo, para os quais foram transplantadas uma muda de tomate cereja cultivar Carolina, espaçados segundo recomendação para a cultura, 1,00 m entre linhas e 0,50m entre plantas.

Para o sistema de irrigação localizada por gotejamento foram utilizadas linhas laterais de tubos $16 \mathrm{~mm}$ e 40 de pressão nominal e tubos de 32 e $25 \mathrm{~mm}$ para demais linhas. Neste sistema de irrigação foram adicionadas válvulas termostáticas e gotejadores "on line" de vazão $1,8 \mathrm{~L} \mathrm{~h}^{-1}$, os quais foram aferidos no decorrer do ensaio. As lâminas de irrigação foram obtidas a partir de dados de um mini tanque evaporímetro confeccionado com PVC de $300 \mathrm{~mm}$ nivelado em um suporte de madeira, conforme Figura 1C. Este foi calibrado em função da evaporação do tanque classe A padrão, durante vinte dias no outono-inverno, sendo identificada a equação de regressão linear (Figura 1B), da qual pode ser estimada a evaporação do tanque classe $A$, assim como a temperatura máxima e mínima do ar (Figura 1A). Nos primeiros dez dias após o transplantio (DAT) a lâmina de irrigação utilizada foi de $100 \%$ da ETc, desta forma assegurou-se o pegamento das mudas.

O cálculo da lâmina de irrigação demandada pela cultura do tomate foi realizado com base na evaporação do minitanque evaporímetro, o qual estava localizado próximo à área de cultivo e instalado sobre estrado de madeira nivelado sobre solo nú, conforme indicação de SALOMÃO (2012). Para isso, diariamente 
foram tomadas medidas da evaporação da água no mini tanque evaporímetro. A evapotranspiração da cultura (ETc) foi estimada pela seguinte equação 1 :

$$
\mathrm{ETc}=\mathrm{Kp} \times \mathrm{Kc} \times \mathrm{Ev} \quad \text { equação } 1
$$

Em que: $\mathrm{ETc}=$ evapotranspiração da cultura $\left(\mathrm{mm} \mathrm{dia}^{-1}\right), \mathrm{Kp}=$ coeficiente do tanque, adimensional $(0,75$ para ambiente protegido); $\mathrm{Kc}=$ coeficiente da cultura (variável em função dos estádios de desenvolvimento do tomateiro); $\mathrm{Ev}$ = evaporação do tanque corrigido para o tanque classe A padrão $\left(\mathrm{mm} \mathrm{dia}^{-1}\right)$.

Para obter a lâmina de irrigação, a partir da porcentagem da ETc, foi usada a equação 2:

$$
\text { Lam }=E T c \times L / 100 \times \text { CUD equação } 2
$$

Em que: Lam = Lâmina de irrigação a ser aplicada em cada tratamento $(\mathrm{mm}) ; \mathrm{ETC}=$ evapotranspiração da cultura $\left(\mathrm{mm} \mathrm{dia}^{-1}\right) ; \mathrm{L}=$ Porcentagem da lâmina de irrigação de acordo com cada tratamento $(50,75,100,125$ ou $150 \%)$; e CUD = coeficiente de uniformidade de distribuição (considerado 0,95).

Dessa forma, as quantidades de água aplicadas em cada lâmina de irrigação, foram de: 309,$5 ; 439,25 ; 569 ; 698,75$ e $828,5 \mathrm{~mm}$ para os tratamentos correspondentes a 50, 75, 100, 125 e $150 \%$ da lâmina requerida pela cultura, respectivamente.

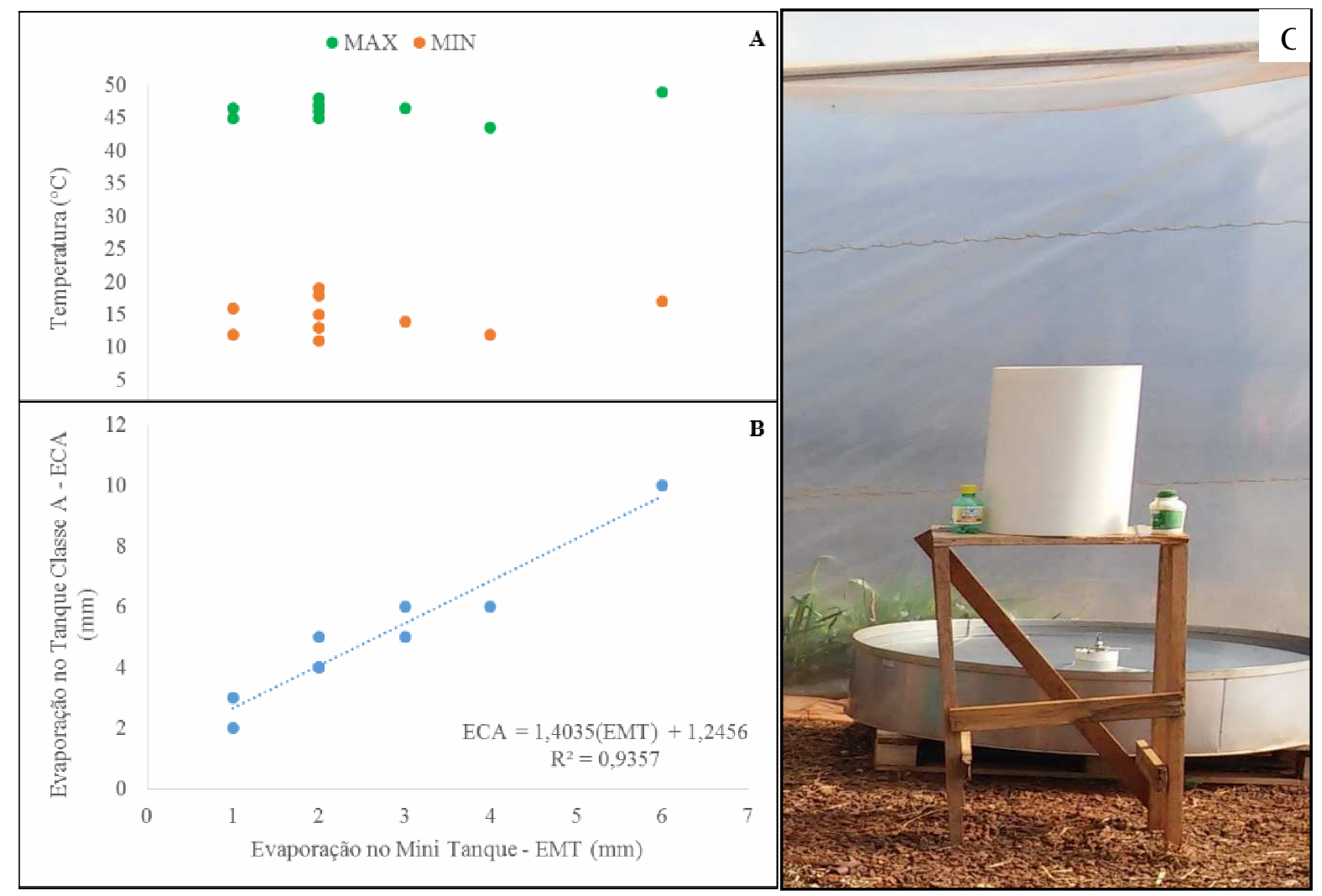

FIGURA 1 - Temperatura máxima e mínima do ar (A) em ambiente protegido durante a calibração do mini tanque evaporímetro com o tanque classe $A$ padrão (C), e sua respectiva equação de calibração (B), em Santa Helena de Goiás. 
Fonte: arquivo pessoal

A adubação foi feita com base na análise química do solo, segundo recomendação de RIBEIRO (1999). A calagem foi realizada para corrigir a acidez e elevar a saturação por bases para 70\%, com aplicação de calcário calcítico de poder real de neutralização total (PRNT) de 100\%. Foram aplicados no transplantio 100\% da dose recomendada de fósforo e $15 \%$ do nitrogênio e potássio, as quantidades restantes foram fornecidas quinzenalmente com incorporação ao solo, seguindo esquema de parcelamento apresentado por RIBEIRO (1999), e detalhado na Tabela 1 .

Para análise do efeito dos tratamentos sobre o crescimento do tomateiro foram mensurados: diâmetro do caule (DC) apresentado em $\mathrm{mm}$ e altura de plantas (AP) dado em $\mathrm{cm}$ nos período de 21, 34, 42, 53 e 74 DAT. O diâmetro do caule foi determinado a $5 \mathrm{~cm}$ do caule das plantas, com auxílio de um paquímetro digital, e a altura de planta medindo-se a distância entre o solo e ápice da planta, com o uso de trena graduada em centímetros.

TABELA 1 - Época e doses de fertilizantes aplicados no solo para o cultivo do tomate irrigado por gotejo sob diferentes lâminas e fontes de nitrogênio, em ambiente protegido na Universidade Estadual de Goiás, Câmpus Santa Helena de Goiás.

\begin{tabular}{|c|c|c|c|c|}
\hline $\begin{array}{l}\text { Época de } \\
\text { Aplicação }\end{array}$ & $\begin{array}{c}\text { DAT (Dias } \\
\text { após } \\
\text { transplantio) }\end{array}$ & $\begin{array}{l}\text { Dose de Nitrogênio } \\
\quad\left(\mathbf{k g} \text { de } \mathrm{N} \mathrm{ha}^{-1}\right)\end{array}$ & $\begin{array}{l}\text { Dose de potássio } \\
\left(\mathbf{k g} \text { de } \mathrm{K}_{2} \mathrm{O} \text { ha }^{-1}\right)\end{array}$ & $\begin{array}{l}\text { Dose de fósforo } \\
\left(\mathbf{k g ~} \mathrm{P}_{2} \mathrm{O}_{5} \mathrm{ha}^{-1}\right)\end{array}$ \\
\hline Transplantio & - & 20 & 60 & 700 \\
\hline 2a Aplicação & 14 DAT & 20 & 90 & 300 \\
\hline 3a Aplicação & 29 DAT & 40 & 90 & - \\
\hline 4⿳亠丷a Aplicação & 42 DAT & 40 & 120 & - \\
\hline 5ª Aplicação & 57 DAT & 40 & 120 & - \\
\hline
\end{tabular}

Os dados obtidos foram submetidos à análise de variância pelo teste $\mathrm{F}$ e nos casos de significância, realizou-se análise de regressão linear e quadrática para o fator lâmina, e teste de Tukey para avaliar o efeito de fontes de nitrogênio e dias após transplantio, utilizando-se do software estatístico SISVAR (FERREIRA, 2011).

\section{RESULTADOS E DISCUSSÃO}

Conforme análise de variância (Tabela 2) constata-se efeito significativo das lâminas de irrigação, dias após transplantio e fontes de nitrogênio para a altura de planta, sendo o diâmetro de caule significativo apenas para os dois últimos fatores de avaliação. Quando se estuda as interações verifica-se efeito significativo para a interação fonte de N e DAT apenas sobre a característica altura de plantas. 


\begin{tabular}{|c|c|c|c|}
\hline \multirow{3}{*}{ FV } & \multirow{3}{*}{ GL } & \multirow{2}{*}{\multicolumn{2}{|c|}{ Valor de F }} \\
\hline & & & \\
\hline & & Altura & Caule \\
\hline Lamina & 4 & $8,13^{* *}$ & 2,19 ns \\
\hline \multirow{2}{*}{$\begin{array}{l}\text { Bloco(Lamina) } \\
\text { Fonte }\end{array}$} & 10 & $1,71^{\text {ns }}$ & 1,39 ns \\
\hline & 4 & $21,79^{* *}$ & $4,72 *$ \\
\hline Lamina*Fonte & 16 & $1,97 \mathrm{~ns}$ & 1,29 ns \\
\hline erro (a) & 40 & - & - \\
\hline DAT & 2 & 840,93 ** & $281,74^{* *}$ \\
\hline DAT*Lamina & 8 & $1,43^{\mathrm{ns}}$ & 1,16 ns \\
\hline DAT*Fonte & 8 & $3,77^{* *}$ & $0,57^{\text {ns }}$ \\
\hline DAT $^{\star}$ Lamina ${ }^{\star}$ Fonte & 32 & $0,63^{\mathrm{ns}}$ & $0,66^{\text {ns }}$ \\
\hline erro (b) & 100 & - & - \\
\hline Total & 224 & - & - \\
\hline CV a (\%) & - & 23,15 & 27,91 \\
\hline CV b (\%) & - & 16,84 & 11,29 \\
\hline
\end{tabular}

FV: fonte de variação; DAT: dias após transplantio de mudas; CV: coeficiente de variação; GL: graus de liberdade; *, ${ }^{* *}$ : significativo a 5 e $1 \%$, respectivamente, pelo Teste de F; "ns : não significativo.

Conforme TAIZ \& ZEIGER (2009), a planta quando em estresse hídrico ou excesso de água tem seu crescimento e desenvolvimento afetados, o que pode ocasionar modificações na anatomia e morfologia, assim como interferir em suas reações metabólicas. Nota-se através da Figura 2, que a altura máxima de plantas de tomate $(43,54 \mathrm{~cm})$ foi atingida com uma lâmina de $111,32 \%$ da ETc, apresentando-se sem efeito para o diâmetro de caule. Com base nestes resultados, confirma-se que o suprimento de água adequado resulta em melhor crescimento de plantas de tomate, tendo como indicador altura de plantas, o que segundo OKUMURA et al. (2013) é um parâmetro relacionado ao vigor de plantas e consequentemente de produtividade. Este resultado reforça os encontrados por SOARES et al. (2011) que ao avaliarem lâminas de irrigação sob as taxas de crescimento de plantas de tomate industrial, não verificaram efeito significativo para a variável diâmetro de caule, e afirmaram que se trata de uma variável pouco vulnerável ao estresse hídrico. 


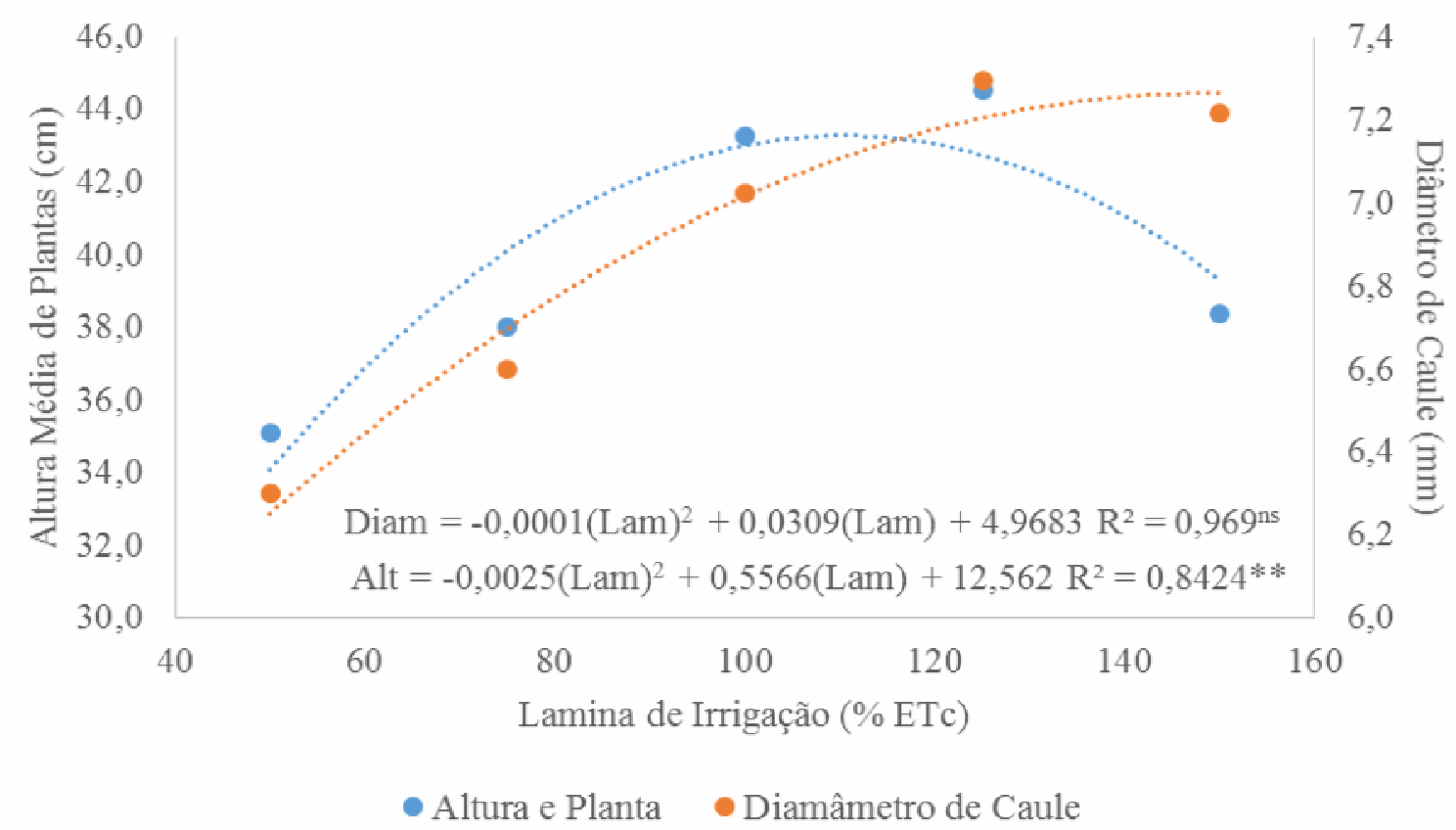

FIGURA 2 - Altura e diâmetro médio de caule de plantas de tomate cereja durante o desenvolvimento vegetativo sob lâminas de irrigação. ${ }^{\text {ns }}$ não significativo $e^{* *}$ significativo a $1 \%$ de probabilidade

Na Figura 3 é apresentada a curva de crescimento do tomateiro cereja, por meio dos parâmetros vegetativos altura de plantas e diâmetro de caule, em função das lâminas de irrigação e das fontes de nitrogênio. As Figuras $3 \mathrm{~A}, \mathrm{C}$ e $\mathrm{E}$ correspondem a altura de plantas para as fontes ureia comum, ureia com inibidor de urease e sem N, respectivamente e as Figuras 3 B, D e F referem-se ao diâmetro de caule para esta mesma sequência. Nota-se maior proporção de crescimento para lâminas intermediárias, sendo que o excesso e/ou a escassez de água interferiram no crescimento das plantas de tomate. MARCHESAN et al. (2013) comparou a produtividade do arroz irrigado sob o efeito de ureia recoberta ou não com inibidor de urease em dois sistemas de cultivo, e concluiu que quando o intervalo entre a aplicação de nitrogênio e de água estão dentro dos níveis indicados, não há vantagem em utilizar a UI em comparação com o uso de UC. 


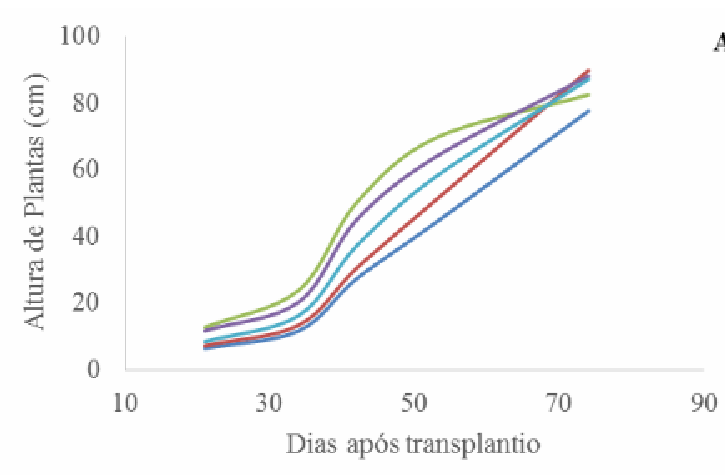

$\mathbf{A}$
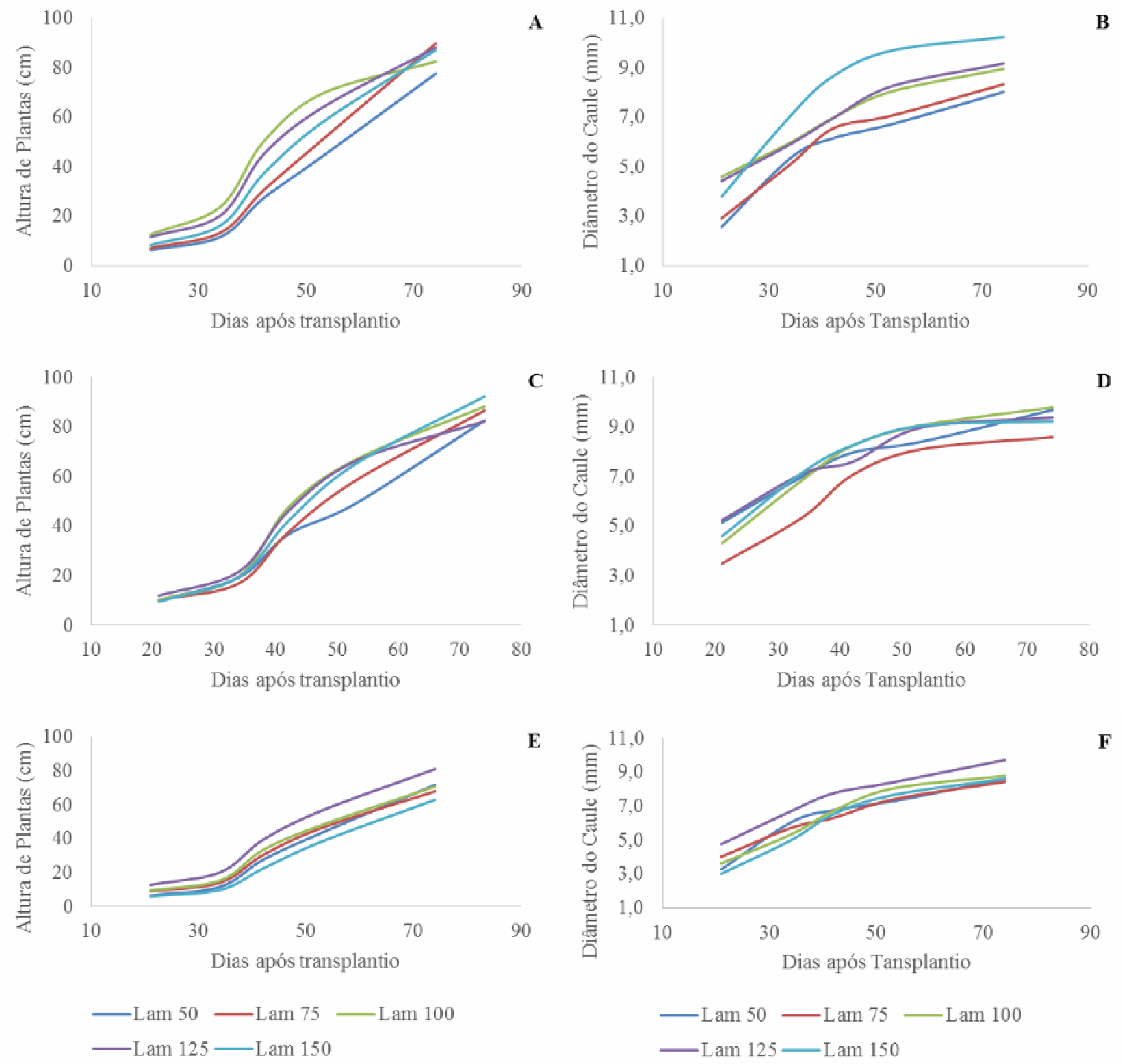

FIGURA 3 - Altura (A, C, E) e diâmetro (B, D, F) durante o desenvolvimento vegetativo do tomate cereja cultivado sob fontes de nitrogênio: ureia comum, ureia com inibidor de uréase e ausência de $\mathrm{N}$, respectivamente, e sob lâminas de irrigação variáveis em função da evapotranspiração da cultura.

SANTANA et al. (2010) ao avaliarem o diâmetro de caule e altura do tomateiro observaram que 0 excesso de água e o déficit hídrico promoveram menores valores destas variáveis, independente da data de coleta. BRITO et al. (2015) avaliaram lâminas de irrigação sob o crescimento e formação de fitomassa do tomateiro e observaram que a irrigação com lâmina de $80 \%$ da evapotranspiração real resultou em aumento de fitomassa, e o estresse hídrico aumentou a porção de caule em relação às folhas, e atribuíram este fato a um mecanismo de tolerância da cultura.

A Tabela 3 indica a interação entre as fontes de nitrogênio e os DAT para a variável altura de plantas. Verifica-se que no primeiro mês após o transplantio das mudas de tomate não foi observada diferença entre a presença ou não de nitrogênio para a altura de plantas, independente da fonte utilizada. No entanto, a partir dos 42 DAT as plantas, independente da fonte de $\mathrm{N}$ empregada, começaram a diferir do 
tratamento sem $\mathrm{N}$, o que indica que este nutriente apresenta efeito sob a altura da planta de tomate a partir deste estádio. Conforme FONTES (2014), a nutrição mineral exerce papel fundamental no desenvolvimento das plantas, principalmente a adubação nitrogenada, pois aceleram o crescimento das mesmas, podendo reduzir os custos de produção (MENDONÇA et al., 2007). Alguns trabalhos afirmam que fertilizantes nitrogenados de liberação lenta elevam a produtividade de diversas culturas como o milho (FRAZÃO et al., 2014), o trigo, quando aplicado em cobertura no perfilhamento (ESPÍNDULA et al., 2014), no entanto para o feijão BERNARDES et al. (2014) e BERNARDES et al. (2015) não encontraram diferenças entre a ureia comum para parâmetros produtivos do feijoeiro, assim como o observado entre as fontes de nitrogênio no que tange a altura de plantas de tomate cereja.

TABELA 3 - Altura de plantas de tomate cereja $(\mathrm{cm})$ em função de número de dias após transplantio de Fontes de nitrogênio, ureia comum, ureia com inibidor de uréase e sem nitrogênio (Sem $\mathrm{N}$ ), cultivado em ambiente protegido em Santa Helena de Goiás.

\begin{tabular}{cccr}
\hline & \multicolumn{4}{c}{ Fonte de Nitrogênio } \\
\cline { 2 - 5 } DAT & $\begin{array}{c}\text { Ureia } \\
\text { Comum }\end{array}$ & $\begin{array}{c}\text { Ureia com } \\
\text { Inibidor }\end{array}$ & Sem N \\
\hline 21 & $9,3 \mathrm{Ad}$ & $10,41 \mathrm{Ad}$ & $8,76 \mathrm{Ad}$ \\
34 & $17,12 \mathrm{Ad}$ & $19,45 \mathrm{Ad}$ & $14,28 \mathrm{Ad}$ \\
42 & $38,03 \mathrm{Abc}$ & $41,93 \mathrm{Ac}$ & $30,73 \mathrm{Bc}$ \\
53 & $57,43 \mathrm{Ab}$ & $61,18 \mathrm{Ab}$ & $46,74 \mathrm{Bb}$ \\
74 & $84,98 \mathrm{Aa}$ & $86,46 \mathrm{Aa}$ & $70,98 \mathrm{Ba}$ \\
\hline
\end{tabular}

Médias seguidas de mesma letra maiúscula na linha e minúscula na coluna não diferem entre si pelo teste de Tukey a $5 \%$ de probabilidade.

\section{CONCLUSÕES}

A altura máxima de plantas de tomate $(43,54 \mathrm{~cm})$ cereja cultivado em vasos em ambiente protegido foi atingida com uma lâmina de $111,32 \%$ da ETc. hídrico.

O diâmetro de caule do tomateiro é uma variável pouco sensível ao estresse

O efeito da adubação nitrogenada em plantas de tomate só foi perceptível aos 42 dias após o transplantio.

\section{REFERÊNCIAS}

BERNARDES, T. G.; SILVEIRA, P. M.; CARVALHO, M. T. M.; MADARI, B. E.; CARVALHO. M. C. S. Produtividade do feijoeiro irrigado em razão de fontes de adubo nitrogenado estabilizado e de liberação controlada. Revista Ceres, v. Viçosa, v. 62, n. 6, p. 614-620, 2015. Disponível em: < http://dx.doi.org/10.5433/16790359.2013v34n1p157> Doi: 10.5433/1679-0359.2013v34n1p157

BERNARDES, T. G. B.; SILVEIRA, P. M.; MESQUITA, M. A. M.; CUNHA, P. C. R. Resposta de feijoeiro outono-inverno a fontes e doses de nitrogênio em cobertura. Biosciense Journal, Uberlândia, v. 30, n. 2, p. 458-468, 2014. 
BRITO, M. E. B.; SOARES, L. A. A.; LIMA, G. S.; SÁ, F. V. S.; ARAÚJO, T. T.; SILVA, E. C. B. Crescimento e formação de fitomassa do tomateiro sob estresse hídrico nas fases fenológicas. Irriga, Botucatu, v. 10, n. 1, p. 139-153, 2015. Disponível em: <http://dx.doi.org/10.15809/irriga.2015v20n1p139> Doi: 10.15809/irriga.2015v20n1p139

CAETANO, A. O.; DINIZ, R. L. C.; BENETT, C G. S.; SALOMÃO, L. C. Efeito de fontes e doses de nitrogênio na cultura do rabanete. Revista de Agricultura Neotropical, Cassilândia, v. 2, n. 4, p. 55-59, 2015.

CAMPAGNOL, R.; ABRAHÃO, C.; MELLO, S. C.; OVIEDO, V. R. S. C.; MINAMI, K. Impactos do nível de irrigação e da cobertura do solo na cultura do tomateiro. Irriga, Botucatu, v. 19, n. 3, p. 345-357, 2014. Disponível em: <http://dx.doi.org/10.15809/irriga.2014v19n3p345> 10.15809/irriga.2014v19n3p345

ESPÍNDULA, M. C.; ROCHA, V. S.; SOUZA, M. A.; CAMPANHARO, M.; PIMENTEL, A. J. B. Urease inhibitor (NBPT) and efficiency of single or split application of urea in wheat crop. Revista Ceres, Viçosa, v. 61, n. 2, p. 273-279, 2014. Disponível em:< http://dx.doi.org/10.1590/S0034-737X2014000200016> Doi: 10.1590/S0034737X2014000200016

FERREIRA, D. F. Sisvar: a computer statistical analysis system. Ciência e Agrotecnologia, Lavras, v. 35, n. 6, p. 1039-1042, 2011. Disponível em: < http://dx.doi.org/10.1590/S1413-70542011000600001> Doi: 10.1590/S141370542011000600001

FRAZÃO, J. J.; SILVA, A. R.; SILVA, V. L.; OLIVEIRA, V. A.; CORRÊA, R. S. Fertilizantes nitrogenados de eficiência aumentada e ureia na cultura do milho, Revista Brasileira de Engenharia Agrícola e Ambiental, Campina Grande, v. 18, n. 12, p. 1262-1267, 2014. Disponível em: http://dx.doi.org/10.1590/18071929/agriambi.v18n12p1262-1267 Doi: http://dx.doi.org/10.1590/18071929/agriambi.v18n12p1262-1267

GUILHERME, D. O.; PINHO, L.; CAVALCANTI, T. F. M.; COSTA, C. A.; ALMEIDA, A. C. Análise sensorial e físico-química de frutos de tomate cereja orgânicos. Revista Caatinga, Mossoró, v. 27, n. 1, p. 181-186, 2014.

MARCHESAN, E.; GROHS, M.; WALTER, M.; SILVA, L. S.; FORMENTINI, T. C. Agronomic performance of rice to the use of urease inhibitor in two cropping systems. Revista Ciência Agronômica, Fortaleza, v. 44, n. 3, p. 594-603, 2013. Disponível em: < http://dx.doi.org/10.1590/S1806-66902013000300023> Doi: 10.1590/S1806-66902013000300023

MENDONÇA, V.; TOSTA, M. S.; MACHADO, J. R.; GOULART JÚNIOR, S. A. R.; TOSTA, J. S.; BISCARO, G. A. Fertilizante de liberação lenta na formação de mudas de maracujazeiro 'amarelo'. Ciência e Agrotecnologia, Lavras, v. 31, n. 2, p. 344348, 2007. Disponível: < http://dx.doi.org/10.1590/S1413-70542007000200012> Doi: 10.1590/S1413-70542007000200012 
OKUMURA, R. S.; YANO, G. T.; MARIANO, D. C.; ZACCHEO, P. V. C.; TAKAHASHI, H. W. Nutrição nitrogenada no milho fertilizado com ureia tratada com inibidor de urease. Revista Semina: Ciências Agrárias, Londrina, v. 34, n. 1, p. 157-170, 2013. Disponível em: http://dx.doi.org/10.5433/1679-0359.2013v34n1p157 Doi: 10.5433/1679-0359.2013v34n1p157

RIBEIRO, A. C.; GUIMARÃES, P. T. G.; ALVAREZ V., V. H. Recomendações para o uso de corretivos e fertilizantes em Minas Gerais, 5a Aproximação, Viçosa: CFSEMG, 1999, 359p.

SALOMÃO, L. C. Calibração de tanques evaporímetros de baixo custo sob diferentes diâmetros em ambiente protegido. 2012. 87 folhas. Tese (Doutorado) Universidade Estadual Paulista "Júlio de Mesquita Filho", Botucatu, São Paulo, 2012.

SANTANA, M. J.; VIEIRA, T. A.; BARRETO, A. C. Resposta do tomateiro irrigado a níveis de reposição de água no solo. Irriga, Botucatu, v. 15, n. 4, p. 443-454, 2010. Disponível em: <http://dx.doi.org/10.15809/irriga.2010v15n4p443> Doi: 10.15809/irriga.2010v15n4p443

SOARES, L. A. A.; LIMA, G. S.; BRITO, M. E. B.; ARAÚJO, T. T.; SÁ, F. V. S. Taxas de crescimento do tomateiro sob lâminas de irrigação em ambiente protegido. Revista Verde de Agroecologia e Desenvolvimento Sustentável, Mossoró, v. 6, n. 2, p. 210-217, 2011.

TAIZ, L.; ZEIGER, E. Fisiologia vegetal. 4ํe․ Porto Alegre: Artmed, 2009.819p 